\title{
Directly cast bulk eutectic and near-eutectic high entropy alloys with balanced strength and ductility in a wide temperature range
}

Yiping Lu ${ }^{1, \dagger}$, Xuzhou Gao ${ }^{2, \dagger}$, Li Jiang ${ }^{1, \dagger}$, Zongning Chen ${ }^{1}$, Tongmin Wang ${ }^{1, *}$, Jinchuan Jie $^{1}$, Huijun Kang ${ }^{1}$,Yubo Zhang ${ }^{1}$, Sheng Guo ${ }^{3, *}$, Haihui Ruan ${ }^{4}$, Yonghao Zhao ${ }^{2}$, Zhiqiang $\mathrm{CaO}^{1}$, Tingju $\mathrm{Li}^{1, *}$

${ }^{1}$ Key Laboratory of Solidification Control and Digital Preparation Technology (Liaoning Province), School of Materials Science and Engineering, Dalian University of Technology, Dalian 116024, P.R. China

2 School of Materials Science and Engineering, Nanjing University of Science and Technology, Nanjing 210094, China

3 Surface and Microstructure Engineering Group, Materials and Manufacturing Technology, Chalmers University of Technology, SE-41296, Gothenburg, Sweden

${ }^{4}$ Department of Mechanical Engineering, The Hong Kong Polytechnic University, Hung Hom, Hong Kong, P. R. China

$\uparrow$ These authors contributed equally to this work.

* Author to whom correspondence should be addressed. E-mail: tmwang@dlut.edu.cn; sheng.guo@chalmers.se; tjuli@dlut.edu.cn Tel.: +86 411 84709400; Fax: +86 411 84708940

\begin{abstract}
High entropy alloys (HEAs) usually possess weak liquidity and castability, and considerable compositional inhomogeneity, mainly because they contain multiple elements with high concentrations. As a result, large-scale production of HEAs by casting is limited. To address the issue, the concept of eutectic high entropy alloys (EHEAs) was proposed, which has led to some promise in achieving good quality industrial scale HEAs ingots, and more importantly also good mechanical properties. In the practical large-scale casting, the actual composition of designed EHEAs could potentially deviate from the eutectic composition. The influence of such deviation on mechanical properties of EHEAs is important for industrial production, which constitutes the topic of the current work. Here we prepared industrial-scale HEAs ingots near the eutectic composition: hypoeutectic alloy, eutectic alloy and hypereutectic alloy. Our results showed that the deviation from eutectic composition does not significantly affect the mechanical properties, castability and the good mechanical properties of EHEAs can be achieved in a
\end{abstract}


wide compositional range, and at both room and cryogenic temperatures. Our results suggested that EHEAs with simultaneous high strength and high ductility, and good liquidity and castability can be readily adapted to large-scale industrial production. The deformation behavior and microstructure evolution of the eutectic and near-eutectic HEAs were thoroughly studied using a combination of techniques, including strain measurement by digital image correlation, in-situ synchrotron X-ray diffraction, and transmission electron microscopy. The wavy strain distribution and the therefore resulted delay of necking in EHEAs were reported for the first time.

Keywords: High entropy alloys; Industrial scale casting; Mechanical properties; Eutectic; In-situ X-ray diffraction

\section{Introduction}

Recently, a new type of alloys, high entropy alloys (HEAs) or multi-principal-element alloys, is becoming new research frontier in the metallic materials community [1-14]. Compared to conventional metallic alloys based on one or two principal elements, HEAs generally contain at least four principal elements. The concept of HEAs is a breakthrough to the alloy design in traditional physical metallurgy, and opens a new field for explorations of new materials and new properties [13, 15]. Although the high configuration entropy in HEAs helps to stabilize solid solutions (against compound phases), previous studies have showed that most HEAs contain multiple phases rather than a single-phase solid solution [2, 16-18]. From the alloy preparation perspective, most HEAs are made by casting, although the powder metallurgy route is also gaining more attention $[19,20]$. Casting of HEAs, particularly at a large scale (kilogram scale) is quite often a challenge, as most HEAs possess weak liquidity and castability (see Fig. S1 
in the Supplementary Information for a demonstration) and considerable chemical inhomogeneity [21], which retards their industrial application. From the mechanical properties perspective, it is already known that in general single-phased body-centered cubic (bcc)-structured HEAs have limited ductility [22], while single-phased facecentered cubic (fcc)-structured HEAs could have high ductility but their strength is low [23]. How to reach the both high strength and high ductility is another challenge for the engineering application of HEAs.

To address the above mentioned problems facing the real application of HEAs, the current authors proposed to use the eutectic alloy concept to design HEAs, aiming at good castability of eutectic alloys and composite structure to resolve the strengthductility trade-off $[21,24]$. Our initial efforts in making eutectic HEAs (EHEAs) have led to kilogram-scale $\mathrm{AlCoCrFeNi}{ }_{2.1}$ HEA with good liquidity and castability, which also exhibits good mechanical properties at both room temperature and elevated temperatures up to $700{ }^{\circ} \mathrm{C}[21]$.

Practically, the actual composition of EHEAs could deviate from the designed eutectic composition, especially for the large-scale casting. How would the deviation from the eutectic composition affect mechanical properties of EHEAs? The acceptable compositional range for desired mechanical properties is certainly important for the industrial production of EHEAs, but remains unexplored. This motivates the current work. Here we prepared industrial-scale ingots near the previously studied eutectic composition, $\mathrm{AlCoCrFeNi}_{2.1}$, and tested how the mechanical properties of EHEAs vary in a compositional range near the eutectic composition. We chose to use directly cast materials for the study, since we are expecting to avoid subsequent thermomechanical 
treatments by developing sufficiently good as-cast materials. Certainly, the performance of as-cast materials that are reported here can be further improved by thermomechanical treatments $[21,24]$.

\section{Experimental}

The master alloy of hypoeutectic $\mathrm{AlCoCrFeNi} \mathrm{N}_{2.0}(\mathrm{Ni} 2.0)$, eutectic $\mathrm{AlCoCrFeNi}{ }_{2.1}(\mathrm{Ni} 2.1)$, and hypereutectic $\mathrm{AlCoCrFeNi}_{2.2}$ (Ni2.2) were prepared from commercially pure elements (Al, Co, Ni: 99.9 wt. \%; Cr, Fe: 99.5 99.6 wt.\%). The raw elements were alloyed in a BN crucible in the vacuum induction melting furnace. The BN crucible was heated to $600{ }^{\circ} \mathrm{C}$ and held for 1 hour to remove the water vapor, before putting into the furnace. The pouring temperature was set to be $1500{ }^{\circ} \mathrm{C}$. An IRTM-2CK infrared pyrometer was employed to monitor the temperature with an absolute accuracy of $\pm 2{ }^{\circ} \mathrm{C}$. Approximately $2.5 \mathrm{~kg}$ of master alloys were melted, superheated and poured into a $\mathrm{MgO}$ crucible with the length of $220 \mathrm{~mm}$, upper inner diameter of $62 \mathrm{~mm}$ and bottom inner diameter of $50 \mathrm{~mm}$. In all cases, the furnace chamber was first evacuated to $6 \times 10^{-2} \mathrm{~Pa}$ and then backfilled with high-purity argon gas to reach $0.06 \mathrm{MPa}$. The microstructure and composition of the alloy were investigated by scanning electron microscope (SEM, Zeiss Supra 55) equipped with an attached X-ray energy dispersive spectrometer (EDS). The phase constitution of the alloy was characterized by the X-ray diffractometer (XRD, Shimadzu XRD-6000) using a $\mathrm{Cu}$ target, with the scanning rate of $4 \% \mathrm{~min}$ and the $2 \theta$ scanning range of $20^{\circ}-100^{\circ}$. Room-temperature (RT) tensile tests were performed using the Instron 5569 testing machine at a constant strain rate of $1 \times 10^{-3} \mathrm{~s}^{-1}$, and the bar-shaped tensile test samples had a gauge length of $20 \mathrm{~mm}$, width of $3 \mathrm{~mm}$ and thickness of $3 \mathrm{~mm}$. Cryogenic tensile tests at $-70{ }^{\circ} \mathrm{C}$ and $-196{ }^{\circ} \mathrm{C}$ were performed on rod-shaped samples with 
a gauge length of $28 \mathrm{~mm}$ and diameter of $5 \mathrm{~mm}$, using a MTS 810 testing machine at an strain rate of $1 \times 10^{-3} \mathrm{~s}^{-1}$. Before tensile tests, the specimens and grips were immersed in a liquid nitrogen bath for about 5-10 min; during tensile tests, the specimens stayed completely submerged in the liquid nitrogen and the temperature was measured by the thermocouple. After stretching to tensile rupture, thin sheets with a thickness of $300 \mu \mathrm{m}$ were cut from the cross section of the gauge areas for microstructure observation using transmission electron microscopy (TEM, JEM-2100F). TEM samples were first mechanically ground to $45 \mu \mathrm{m}$ in thickness, then punched into foils with a diameter of 3 $\mathrm{mm}$, and finally thinned by a twin-jet electropolisher using the electrolyte made of 90 vol. \% alcohol and 10 vol. \% perchloric acid at a voltage of $20 \mathrm{kV}$. To further understand the deformation behavior, the strain field of the $\mathrm{AlCoCrFeNi}_{2.1}$ EHEA sheet within the gauge length was further mapped by the Nakazima test (strain measurement by digital image correlation, SMDIC, see Fig. S2). Tensile tests were carried out on a Series LFM$20 \mathrm{kN}$ electromechanical universal testing machine with a strain rate of $1 \times 10^{-3} \mathrm{~s}^{-1}$ at room temperature. Bar-shaped tensile samples with a gauge length of $20 \mathrm{~mm}$, width of $3 \mathrm{~mm}$ and thickness of $\sim 2 \mathrm{~mm}$ were grounded and polished before tension. The measurement to evaluate the strain needs an initial high-contrast stochastic pattern of spots on the outer surface of the test sample, which was achieved by first spraying a background of adhesive and flexible matte white paint on the tensile samples, and then spraying a fine layer of spots of black paint onto the background. From the beginning of loading to the final failure, the evolution of the black spots was recorded using two CCD cameras positioned in a non-symmetrical configuration: first one directly in front of the specimen and the second one at about 32 degrees to the normal direction of the specimen. This 
setting allows performing 3D DIC analysis. The CCD camera recorded 2 images per second during the tension test, which were processed using the ARAMIS software to determine the full-field displacements. For understanding the phase transformation during the tensile testing, in-situ synchrotron XRD analysis was carried out on the 4W1A beamline at Beijing Synchrotron Radiation Facility (BSRF), China. The synchrotron Xray with the wavelength of $1.54 \AA$ was irradiated on the tensile test sheets from the beginning of loading to final fracture. Dogbone-shaped specimens with a gauge length of $13 \mathrm{~mm}$ and cross-section of $3 \mathrm{~mm} \times 1 \mathrm{~mm}$ were uniaxially tensile tested using a specially designed testing device (see Fig. S3) at a stretching speed of $10 \mu \mathrm{m} \mathrm{s}^{-1}$. Before testing, the specimens were grinded, polished and cleaned with alcohol. The tensile specimen was positioned at $45^{\circ}$ from the incident beam, while a fan-shaped detector with the apex angle of $120^{\circ}$ was set at the direction of the emergent beam (Fig. S4 and S5). The incident beam and the detector were kept within the same plane. The scanning range was set from $20^{\circ}$ to $160^{\circ}$, as main peaks are concentrated in this range. The diffraction patterns were collected every per 30 seconds. Then diffraction angle $2 \theta$ corresponding to the (hkl) crystal plane was converted to the lattice spacing, $d$, using the Bragg's law. The lattice strain perpendicular to the (hkl) crystal plane was determined from the shifts of the lattice spacing. Specifically, the lattice strains $\varepsilon_{\mathrm{hkl}}$ during an applied load can be calculated from the equation $\varepsilon_{\mathrm{hkl}}=\left(\mathrm{d}_{\mathrm{hkl}}-\mathrm{d}_{\mathrm{hkl}, 0}\right) / \mathrm{d}_{\mathrm{hkl}, 0}$, in which $\mathrm{d}_{\mathrm{hkl}}$ is determined from the hkl reflection during tension, and $\mathrm{d}_{\mathrm{hk}, 0}$ refers to the value for zero load. Finally, lattice strain as a function of loading time for five families of (hkl) crystal planes were obtained during the tensile loading at RT. 


\section{Results and discussion}

\subsection{Microstructure and phase identification}

Industrial scale $\mathrm{AlCoCrFeNi}$ ( prepared. All the ingots exhibited an excellent castability during the casting process, similar to most conventional eutectic alloys. SEM images of the cast microstructure of Ni2.0, Ni2.1 and Ni2.2 ingots are shown in Fig.1 (a-c). Even at such a large ingot, the dominating microstructure in hypoeutectic (Ni2.0) and hypereutectic (Ni2.2) HEAs are fairly uniform and fine lamella, very similar to those in the EHEA (Ni2.1), except for the existence of some small amounts of primary phases. Inter-lamellar spacing in all three HEAs ingots are about $1 \sim 3 \mu \mathrm{m}$. According to the microstructure and EDS analysis, the hypoeutectic Ni2.0 alloy comprises a small amount of primary NiAl-rich phase plus eutectic FeCr-rich phase/NiAl-rich phase, while the hypereutectic Ni2.2 alloy comprise a small amount of primary FeCr-rich phase plus eutectic FeCr-rich phase/NiAl-rich phase. The FeCr-rich phase and NiAl-rich phase have been previously identified to be fcc and B2 phase, respectively [21]. The XRD patterns shown in Fig. 2 further confirm that only a mixture of fcc and B2 phases are observed in Ni2.0, Ni2.1 and Ni2.2 HEAs, and the amount of fcc phase increases when the alloy compositions shifts from hypoeutectic to hypereutectic composition, in agreement with the microstructural observation. TEM observations (see section 3.5 and Ref. [24]) further show that the fcc phase is actually ordered, with the $\mathrm{L}_{2}$ structure.

\subsection{Tensile properties}

The hypoeutectic Ni2.0 and hypereutectic Ni2.2 alloys exhibit a combination of both high 
strength and high ductility, close to that of the Ni2.1 EHEA. Specifically, from the RT engineering stress-strain curves given in Fig. 3(a), the yield and fracture stresses of Ni2.0, Ni2.1 and Ni2.2 alloys are almost the same, which are $\sim 545 \mathrm{MPa}$ and $\sim 1100 \mathrm{MPa}$, respectively. Ni2.0 and Ni2.1 alloys fracture at 16-17\% elongation, while that of the hypereutectic Ni2.2 alloy reaches $\sim 20 \%$, owing to the highest content of the soft fcc phase among three alloys.

The engineering stress-stain curves for Ni2.0, Ni2.1 and Ni2.2 alloys at cryogenic temperatures are shown in Fig. 3(b,c). At $-70{ }^{\circ} \mathrm{C}$, the yield stress, fracture stress and elongation of Ni2.0, Ni2.1 and Ni2.2 alloys are $580 \mathrm{MPa} / 1034 \mathrm{MPa} / 10.5 \%, 595$ $\mathrm{MPa} / 1168 \mathrm{MPa} / 15.8 \%, 570 \mathrm{MPa} / 1143 \mathrm{MPa} / 18.0 \%$, respectively. Compared to the RT properties, both the yield strength and fracture strength increase slightly, which is in trade-off of elongation. Still, a quite good combination of strength and ductility is maintained at $-70{ }^{\circ} \mathrm{C}$, from hypoeutectic to eutectic to hypereutectic alloys. At even lower temperature of $-196{ }^{\circ} \mathrm{C}$, the yield strength continues to increase, to $\sim 700 \mathrm{MPa}$ for all three alloys, while the ductility decreases sharply, to $4 \%$ for hypoeutectic Ni2.0 alloy which contains more hard/brittle $\mathrm{B} 2$ phase, and to $7 \%$ and $9 \%$ for eutectic and hypereutectic alloys. The early fracture also limits the fracture strength of three alloys to 1000-1100 MPa. With decreasing temperature, dislocation motions become more difficult due to the reduced thermal energy for crossing Peierls-Nabarro barriers, and more dislocations accumulate inside the crystal before moving out to accommodate the plastic strain, thus leading to less ductility. This scenario is more severe in the bcc phase than in the fcc phase due to the much higher temperature sensitivity of the Peierls-Nabarro force in the former $[23,25]$, which explains why the hypoeutectic Ni2.0 alloy containing more 
of bec phase shows the lowest ductility at $-196{ }^{\circ} \mathrm{C}$, while the hypereutectic Ni2.2 alloy containing more fcc phase can keep a decent ductility (of $\sim 9 \%$ elongation) at the same temperature.

Fig. 4 shows the fracture surface morphology of the as-cast Ni2.1 EHEA at cryogenic temperatures and at room temperature. Ni2.0 and Ni2.2 alloys present similar fracture morphology, so only the Ni2.1 alloy is chosen for analysis here. For the same reason, only results from the Ni2.1 alloy are given in the following discussions to represent all three alloys unless otherwise stated. As shown in Fig. 4, the fracture surface features mainly trench-like microstructures. By connecting the fcc/B2 composite structure in the Ni2.1 EHEA, it is reasonable to infer the formation mechanism of these trench-like microstructures: during the tensile deformation, the hard B2 phase is barely deformed while the soft fcc phase is stretched; the fcc phase then gradually becomes thinner and edges up, leaving the barely deformed bcc phase at the bottom of the trench. This assumption is supported by the EDS analysis made at the fractured surface. The fact that there exist more trench-like microstructures in the $-196{ }^{\circ} \mathrm{C}$ fractured alloy also lends support to the above given argument on the temperature-sensitive flow stress of the bcc phase.

\subsection{The Nakazima test}

It is of interest to note that although presenting a large ductility, necking is not obvious in tensile tests at both RT and cryogenic temperatures (see Fig. 5(a)). The mechanism for this peculiar deformation deserves further studies. The Nakazima tests (SMDIC) were therefore conducted to map the full-field strain distribution. Besides the eutectic and near-eutectic HEAs, the as-cast fcc-structured pure Ni and bcc-structured 
pure Fe specimens were also tested for comparison. Fig. 5(b) shows the strain field of the EHEA specimen within the gauge length at different stages during tension. In the early stages of deformation, the strain is distributed almost uniformly throughout the entire loading area. After a few seconds, strain localization occurs within a narrow band at some location. Subsequently, the other strain localization appears at a new location. During the course of deformation, it is found that the high-strain and the low-strain regions alternatively appear, exhibiting a wavy strain distribution. This feature is in line with the negligible necking observed in three types of HEAs, which however is markedly different from the conventional understanding of deformation behavior of strain-hardening materials. If the strain hardening rate is uniform, strain localization should occur in one narrow zone, which leads to necking and fracture. This is the case for pure $\mathrm{Ni}$ and $\mathrm{Fe}$ as shown in Fig. 5(c,d). For both pure Ni and pure Fe, the strain is first distributed almost uniformly within the gauge length at the early stages of loading. With further deformation, the strain starts to localize in just one narrow band (much faster in bcc-Fe compared to fcc-Ni), finally leading to the necking and fracture of the tensile sample. The distinct deformation behavior of EHEAs in comparison with pure metals may be understood from a soft region/hard region composite structure assumption. During tensile deformation, the softer region will deform first, while the hard regions will stay less deformed. With further deformation, the soft region becomes sufficiently hardened such that the initially hard region start to undergo more deformation (strain). As the deformation goes on, the alternation of soft and hard regions leads to the wavy strain distribution, as is shown in Fig. 5(b). It should be stressed that the "wave length" of the wavy strain field observed in Fig. 5(b) is much larger than the width of fcc and B2 lamella. Therefore, the soft and hard 
regions are not simply corresponding to the soft fcc and hard B2 lamella in the microstructure. Our understanding of deformation behavior of EHEA at this stage is merely qualitative. The main point is that the actual hardening behavior in EHEA is not uniform, which leads to the non-uniform strain field during the whole course of plastic deformation till fracture. From the perspective of the phase constitution in the eutectic alloy, the hard B2 phase renders the alloy with high strength, while the soft fcc phase enables the alloy to have some decent ductility. Such a combination brings about the good balance of high strength and high ductility in the EHEA. However, the very limited deformability of the hard B2 phase also restricts the further deformation of the alloy (Fig. 4). To the best of our knowledge, this is the first time that such a wavy distribution of strain is reported in HEAs and even in metallic materials. The therefore resulted effective delay of necking (and failure) is of significant importance for engineering materials in service.

\subsection{In-situ synchrotron X-ray diffraction test}

The simultaneous achievement of high strength and high ductility in large-scale directly cast hypoeutectic, eutectic and hypereutectic HEAs is quite appealing, which is also seldom seen in both conventional alloys and other HEAs reported previously, at the as-cast state. It is intriguing to understand whether any phase transformation occurs during the deformation process. For this purpose, in-situ synchrotron XRD under uniaxial tensile loading at RT was conducted for the Ni2.1 EHEA. Fig. 6(a) shows the diffraction patterns taken from the tensile test specimen, from the beginning of loading to the final fracture. No phase transformation can be detected, suggesting the combination of high strength and high ductility does not originate from phase transformations. Fig. 6(b) shows 
the variation of lattice strain with loading time for five different crystallographic planes, indicating a strong elastic anisotropy. It can be seen that $\{200\}$ and $\{311\}$ planes have the lowest elastic modulus, while $\{220\}$ and $\{222\}$ planes have the highest. For the Ni2.1 EHEA with the fcc/B2 composite structure, its deformation behavior is quite similar to that of traditional fcc alloys and other fcc-structured HEAs [26]. This scenario also echoes our previous argument for the decent but still limited ductility in the EHEA due to the role B2 phase plays. It is worth noting that $\{200\}$ and $\{311\}$ planes of the $\mathrm{AlCoCrFeNi}_{2.1}$ EHEA can sustain larger lattice strain compared to the fcc-structured HEA reported previously [26], of above $\sim 0.004$ and $\sim 0.003$ till tensile fracture. The apparent reason for the larger lattice strain in $\{200\}$ and $\{311\}$ planes is due to the lower elastic moduli in these planes, which can be immediately seen by comparing Fig. 6(b) with a similar plot measured for fcc-structured CoCrFeMnNi HEA in Ref. [26]. The elastic modulus on $\{311\}$ planes is quite close to that on $\{200\}$ planes, and it is noted that this also differs to the case for $\mathrm{CoCrFeMnNi}$, where the elastic modulus on $\{311\}$ planes is noticeably higher than that on $\{200\}$ planes. It is of great interest to look further into the seemingly peculiar elastic behavior of the EHEA, and specifically why the elastic moduli on $\{200\}$ and $\{311\}$ planes are close and much lower than those on other planes, which however is not the focus of the current work and will be addressed separately.

\subsection{TEM analysis}

TEM analysis was performed to further identify the structure of these eutectic and near-eutectic HEAs after tensile testing. The dark lamellar structure in Fig. 7(a) is confirmed to correspond to the B2 phase, while the light lamellar structure corresponds to the ordered fcc $\left(\mathrm{L1}_{2}\right)$ phase, with their diffraction patters given in Fig. 7(b,c). TEM 
results confirm that the Ni2.1 EHEA after tensile testing still comprise a mixture of (ordered) fcc and B2 phase, and there is no new phase formed during the tensile testing process, in agreement with the in-situ synchrotron XRD result. Fig. 8 displays the microstructure of the Ni2.1 EHEA after tensile fracture. It is clear that a large number of dislocations occur in the soft fcc phase, while no obvious dislocation are observed in the hard/brittle B2 phase. Dislocation slip was blocked in the fcc/B2 phase boundary. A higher dislocation density is seen in the fcc phase near the fcc/B2 phase boundary, compared to the dislocation density further inside the fcc phase. Except for dislocations, no detectable twinning was observed under TEM. It is therefore experimentally confirmed that the easy motion of dislocations in the soft fcc phase provides the N2.1 EHEA with high ductility, and the block-up of dislocations at the fcc/B2 phase boundaries provides the EHEA with high strength. Moreover, the long and straight dislocations and high density of dislocation debris demonstrate the strong interaction of multiple slip systems at room temperature.

\section{Application potential of EHEAs in cryogenic environments}

The simultaneous achievement of good castability and chemical homogeneity, and both high strength and high ductility at both room temperature and cryogenic temperatures, in directly cast industrial-scale EHEAs, provides these materials with great application potential in environments requiring directly cast materials (no subsequent thermomechanical treatment) with superior properties. Cryogenic environments, for example, can be the ideal occasion where EHEAs can find their applications. We use the propeller blades of the icebreaker as a specific example here to explain how directly-cast EHEAs can be the material of the choice in such an environment. An icebreaker is a 
special-purpose designed ship to move and navigate through ice-covered waters (in particular the Arctic, is opening up new waterways and international trade route), and provide safe waterways for other ships. The external components of the icebreaker's propulsion system, including propellers and propeller shafts, determines its ability to propel itself onto the ice, break it, and clear the debris from its path successfully, are therefore essential for its safety. Mainly due to their irregular shape and large volume, propeller blades are prepared by direct casting and are not subject to subsequent thermomechanical treatments to further improve the mechanical performance. Thus, the directly cast materials need to satisfy the demanding application environments. The materials used for propeller blades of icebreakers must have high strength and high impact toughness (therefore high ductility) at low temperatures. Stainless steel and bronze are commonly used materials for propeller blades [27], but there remains a large room for these two materials to improve. Bronze have good castability and high ductility but its low strength is a concern, while stainless steels have poorer castability and their strength is also not high enough. The newly developed EHEAs, with excellent castability and chemical homogeneity and relatively low density $\left(\sim 7.38 \mathrm{~g} / \mathrm{cm}^{3}[21]\right)$ can therefore be the (much) better alternative materials for propeller blades. Our results also show that EHEAs containing high amount of $\mathrm{Cr}$ and $\mathrm{Al}$, possess quite good corrosion resistance in the sea water (the potentiodynamic polarization curves of $\mathrm{AlCoCrFeNi}_{2.1}$ EHEA in 3.5\% $\mathrm{NaCl}$ solution, the simulated seawater environment, is given in Fig. S6), which is also a necessary material property as propeller blade materials.

\section{Summary}

To conclude, large-scale $(\sim 2.5 \mathrm{Kg})$ eutectic and near-eutectic $\mathrm{AlCoCrFeNi}_{\mathrm{x}}(\mathrm{x}=2.0$, 
2.1 and 2.2) HEAs with alternating fine $\mathrm{L} 1_{2} / \mathrm{B} 2$ lamellar structure were prepared, and their mechanical properties were evaluated at both room temperature and cryogenic temperatures. Tensile tests show that directly cast eutectic HEAs can exhibit both high strength and ductility in a comfortable compositional range, and also in a wide temperature range, which outperform most of conventional cast alloys and also HEAs reported previously. The deformation behavior and microstructure evolution of the eutectic and near-eutectic HEAs were carefully investigated by strain measurement using digital image correlation, in-situ synchrotron X-ray diffraction, and TEM. It is found for the first time that the strain field of the EHEA shows a wavy distribution and almost no necking occurs before fracture. The deformation behavior of EHEAs differs significantly from those of conventional fcc- and bcc-structured metals. The fine lamellar microstructure comprising fcc and B2 phase, and the related existence of soft and hard regions in EHEAs, effectively delays the onset of necking. The good ductility of the EHEA is mainly provided by the dislocation motion in the soft fcc phase, while the pileup of dislocations at the fcc/B2 phase boundaries provides the alloy with high strength, which however also limits the further deformation of the alloy. No detectable phase transitions occurred during deformation and no deformation twins were observed after the tensile testing. Our results further convince that EHEAs have great potential in industrial applications, for example in ship propulsion systems.

\section{Acknowledgments}

This research was supported by the National Science Foundation of China (Nos. 51525401, 51471044 and 51671044), the Fundamental Research Funds for Central Universities, Key Laboratory of Basic Research Projects, Department of Education of 
Liaoning Province (LZ2014007), and the Natural Science Foundation of Liaoning

Province (2014028013). SG acknowledges the startup grant from Areas of Advance Materials Science at Chalmers University of Technology and the Junior Researcher Grant from the Swedish Research Council under grant 2015-04087. The research leading to these results has received funding from the People Programme (Marie Curie Actions) of the European Union's Seventh Framework Programme (FP7/2007-2013) under REA grant agreement no 608743 .

\section{References}

[1] B. Gludovatz, A. Hohenwarter, D. Catoor, E. H. Chang, E. P. George, R. O. Ritchie, A fracture-resistant high-entropy alloy for cryogenic applications, Science 345 (2014) $1153-1158$.

[2] O. N. Senkov, J. D. Miller, D. B. Miracle, C. Woodward, Accelerated exploration of multi-principal element alloys with solid solution phases, Nat. Commun. 6 (2015) 6529.

[3] C. Zhu, Z.P. Lu, T.G. Nieh, Incipient plasticity and dislocation nucleation of FeCoCrNiMn high-entropy alloy, Acta Mater. 61 (2013) 2993-3001

[4] Z. Wu, Y. Gao, H. Bei, Thermal activation mechanisms and Labusch-type strengthening analysis for a family of high-entropy and equiatomic solid-solution alloys, Acta Mater. 120 (2016) 108-119.

[5] J.Y. He, H. Wang, H.L. Huang, X.D. Xu, M.W. Chen, Y. Wu, et al., A precipitationhardened high-entropy alloy with outstanding tensile properties, Acta Mater. 102 (2016) 187-196.

[6] Z. Li, K.G. Pradeep, Y. Deng, D. Raabe, C.C. Tasan, Metastable high-entropy dualphase alloys overcome the strength-ductility trade-off, Nature 534 (2016) 227-230.

[7] Z. Zhang, M.M. Mao, J. Wang, B. Gludovatz, Z. Zhang, S.X. Mao, et al., Nanoscale origins of the damage tolerance of the high-entropy alloy $\mathrm{CrMnFeCoNi}$, Nat. Commun. 6 (2015) 10143.

[8] J.Y. He, W.H. Liu, H. Wang, Y. Wu, X.J. Liu, T.G. Nieh, et al., Effects of Al addition on structural evolution and tensile properties of the $\mathrm{FeCoNiCrMn} \mathrm{high-entropy} \mathrm{alloy}$ system, Acta Mater. 62 (2014) 105-113.

[9] Z. Wang, I. Baker, Z. Cai, S. Chen, J.D. Poplawsky,W. Guo, The effect of interstitial carbon on the mechanical properties and dislocation substructure evolution in $\mathrm{Fe}_{40.4} \mathrm{Ni}_{11.3} \mathrm{Mn}_{34.8} \mathrm{Al}_{7.5} \mathrm{Cr}_{6}$ high entropy alloys, Acta Mater. 120 (2016) 228-239.

[10] W.H. Liu, Z.P. Lu, J.Y. He, J.H. Luan, Z.J. Wang, B. Liu, et al., Ductile CoCrFeNiMox high entropy alloys strengthened by hard intermetallic phases, Acta Mater. 116 (2016) 332-342. 
[11] J.W. Yeh, S.K. Chen, S.J. Lin, J.Y. Gan, T.S. Chin, T.T. Shun, et al., Nanostructured high-entropy alloys with multiple principal elements: novel alloy design concepts and outcomes, Adv. Eng. Mater. 6 (2004) 299-303,.

[12] B. Cantor, I.T.H. Chang, P. Knight, A.J.B. Vincent, Microstructural development in equiatomic multicomponent alloys, Mater. Sci. Eng. A 375-377 (2004)213-218.

[13] Y. Zhang, T.T. Zuo, Z. Tang, M.C. Gao, K.A. Dahmen, P.K. Liaw, Z.P. Lu, Microstructures and properties of high-entropy alloys, Prog. Mater. Sci. 61 (2014)193.

[14] Z.P. Lu, H. Wang, M.W. Chen, I. Baker, J.W. Yeh, C.T. Liu, et al., An assessment on the future development of high-entropy alloys: Summary from a recent workshop, Intermetallics 66 (2015) 67-76.

[15] M.C. Gao, J.-W. Yeh, P.K. Liaw, Y. Zhang, High-Entropy Alloys: Fundamentals and Applications, Springer, Cham, Switzerland, 2016.

[16] F. Otto, Y. Yang, H. Bei, E.P. George, Relative effects of enthalpy and entropy on the phase stability of equiatomic high-entropy alloys, Acta Mater. 61 (2013) 2628-2638.

[17] D.J.M. King, S.C. Middleburgh, A.G. McGregor, M.B. Cortie, Predicting the formation and stability of single phase high-entropy alloys, Acta Mater. 104 (2016) $172-179$.

[18] X.D. Xu, P. Liu, S. Guo, A. Hirata, T. Fujita, T.G. Nieh, et al., Nanoscale phase separation in a fcc-based CoCrCuFeNiA10.5 high-entropy alloy, Acta Mater. 84 (2015) 145-152.

[19] Z. Fu, W. Chen, H. Wen, D. Zhang, Z. Chen, B. Zheng,et al., Microstructure and strengthening mechanisms in an FCC structured single-phase nanocrystalline $\mathrm{Co}_{25} \mathrm{Ni}_{25} \mathrm{Fe}_{25} \mathrm{Al}_{7.5} \mathrm{Cu}_{17.5}$ high-entropy alloy, Acta Mater. 107 (2016) 59-71.

[20] S.Varalakshmi, M. Kamaraj, B.S. Murty, Synthesis and characterization of nanocrystalline AlFeTiCrZnCu high entropy solid solution by mechanical alloying, J. Alloy. Compd. 460 (2008) 253-257.

[21] Y. Lu, Y. Dong, S. Guo, L. Jiang, H. Kang, T.Wang, et al., A promising new class of high-temperature alloys: Eutectic high-entropy alloys, Sci. Rep. 4 (2014) 6200.

[22] O.N. Senkov, G.B.Wilks, J.M. Scott, D.B. Miracle, Mechanical properties of $\mathrm{Nb}_{25} \mathrm{Mo}_{25} \mathrm{Ta}_{25} \mathrm{~W}_{25}$ and $\mathrm{V}_{20} \mathrm{Nb}_{20} \mathrm{Mo}_{20} \mathrm{Ta}_{20} \mathrm{~W}_{20}$ refractory high entropy alloys, Intermetallics 19 (2011) 698-706.

[23] C. Varvenne, A. Luque, W.A. Curtin, Theory of strengthening in fcc high entropy alloys, Acta Mater. 118 (2016) 164-176.

[24] Wani, I., Bhattacharjee, T., Sheikh, S., Lu, Y., Chatterjee, S., Bhattacharjee, P., Materials Research Letters, DOI:10.1080/21663831.2016.1160451 (2016) 1.

[25] Otto, F., Dlouhý, A., Somsen, C., Bei, H., Eggeler, G., George, E. P., The influences of temperature and microstructure on the tensile properties of a $\mathrm{CoCrFeMnNi}$ highentropy alloy, Acta Materialia, 61 (2013) 5743.

[26] Y. Wu, W.H. Liu, X.L.Wang, D. Ma, A.D. Stoica, T.G. Nieh,et al. In-situ neutron diffraction study of deformation behavior of a multi-component high-entropy alloy, Appl. Phys. Lett. 104 (2014) 051910.

[27] Carlton, J. Marine Propellers and Propulsion, 3rd Edition. Oxford, UK: ButterworthHeinemann, 2012. 


\section{Figure captions}

Fig. 1. SEM image showing the microstructure of the bulk AlCoCrFeNix (x =2.0, 2.11 , and 2.2) alloys: (a) hypoeutectic $\mathrm{AlCoCrFeNi}{ }_{2.0}$ alloy; (b) eutectic $\mathrm{AlCoCrFeNi}_{2.1}$ alloy, and (c) hypereutectic $\mathrm{AlCoCrFeNi} 2.2$ alloy.

Fig. 2. XRD pattern of $\mathrm{AlCoCrFeNi}_{\mathrm{x}}(\mathrm{x}=2.0,2.1$ and 2.2) alloys.

Fig. 3. Engineering tensile stress-strain curves of $\operatorname{AlCoCrFeNix}(\mathrm{x}=2.0,2.1$ and 2.2) alloys. at RT (a), at $-70{ }^{\circ} \mathrm{C}$ (b), and at $-196{ }^{\circ} \mathrm{C}$ (c).

Fig. 4. Fracture surface morphology of the AlCoCrFeNi 2.1 EHEAs: (a) at $-196{ }^{\circ} \mathrm{C}$; (b) at $-70{ }^{\circ} \mathrm{C}$; (c) at RT.

Fig. 5. Appearance of the tensile specimen at the end of the Nakazima test (a); Nakazima test results measured at different time steps (stages) during tension: (b) the strain field of the AlCoCrFeNi ${ }_{2.1}$ EHEA, presenting wave-like distribution; (c) and (d) the strain field of the pure $\mathrm{Ni}$ and pure Fe metal, showing the evolution of strain localization and necking development.

Fig. 6. (a) Selected X-ray diffraction patterns collected at different time steps during tensile loading at RT. (b) Loading time versus lattice strain curves for five crystal planes obtained during tensile loading at RT. The stresses at the $5^{\text {th }}, 10^{\text {th }}, 15^{\text {th }}, 20^{\text {th }}$ and $25^{\text {th }}$ minute of the tensile testing process are extracted from the recorded stress as a function of loading time, and indicated on the plot.

Fig. 7. TEM images from the tensile Ni2.1 EHEA specimen stretched to fracture at RT:

(a) Bright-field image showing the lamellar structure; (b) and (c) are the SADP (selected-area diffraction pattern) corresponding to the $\mathrm{L}_{2}$ and $\mathrm{B} 2$ phase, respectively. Superlattice diffraction spots are indicated by circles.

Fig. 8. TEM images from the tensile Ni2.1 EHEA specimen stretched to fracture at RT: (a) a large number of dislocations are observed in the $\mathrm{L}_{2}$ phase, but not in the $\mathrm{B} 2$ phase; (b) dislocations within the $\mathrm{L1}_{2}$ phase. 


\section{Lu YP, et al., Fig. 1(a-c)}
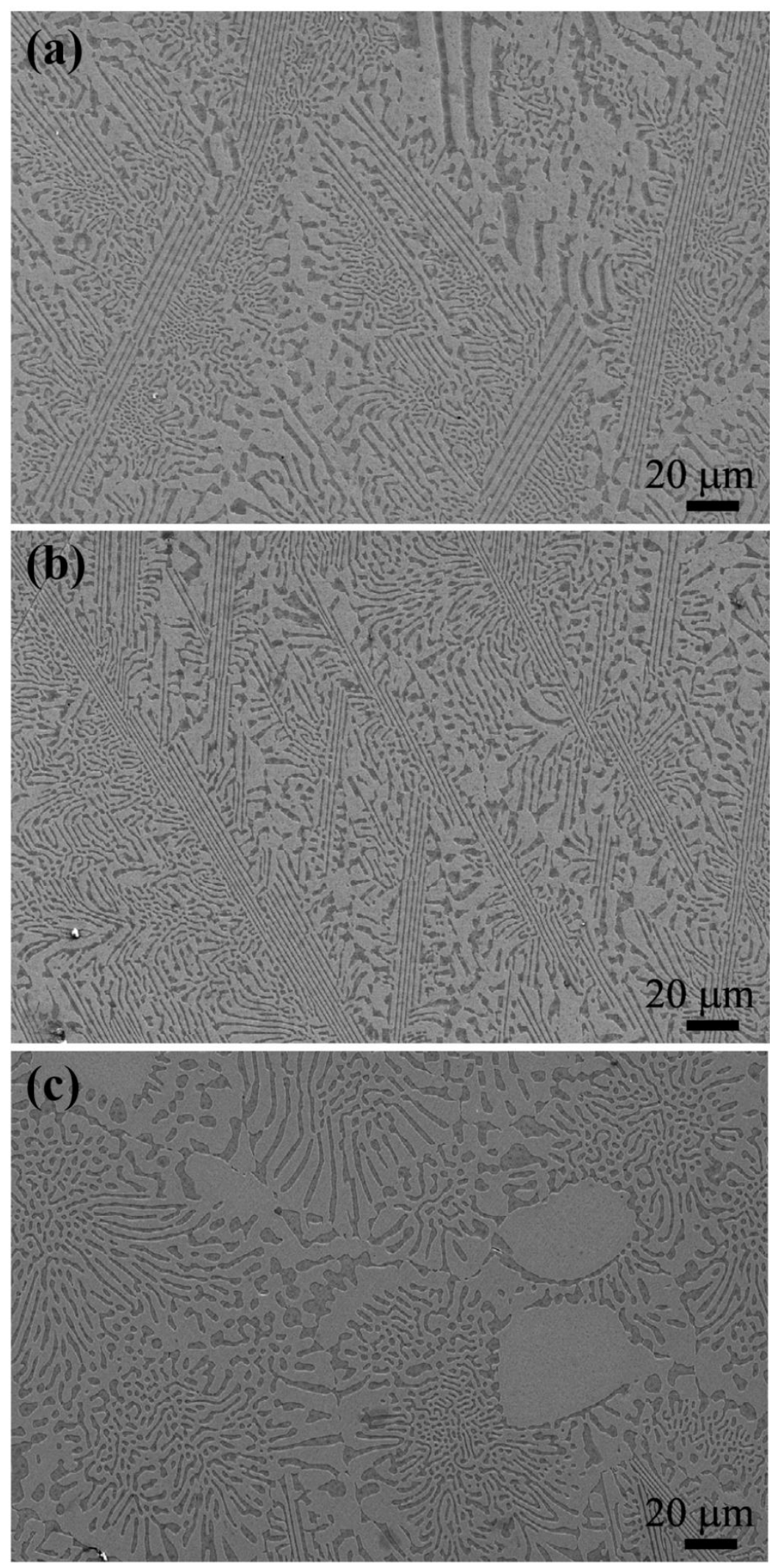
Lu YP, et al., Fig. 2

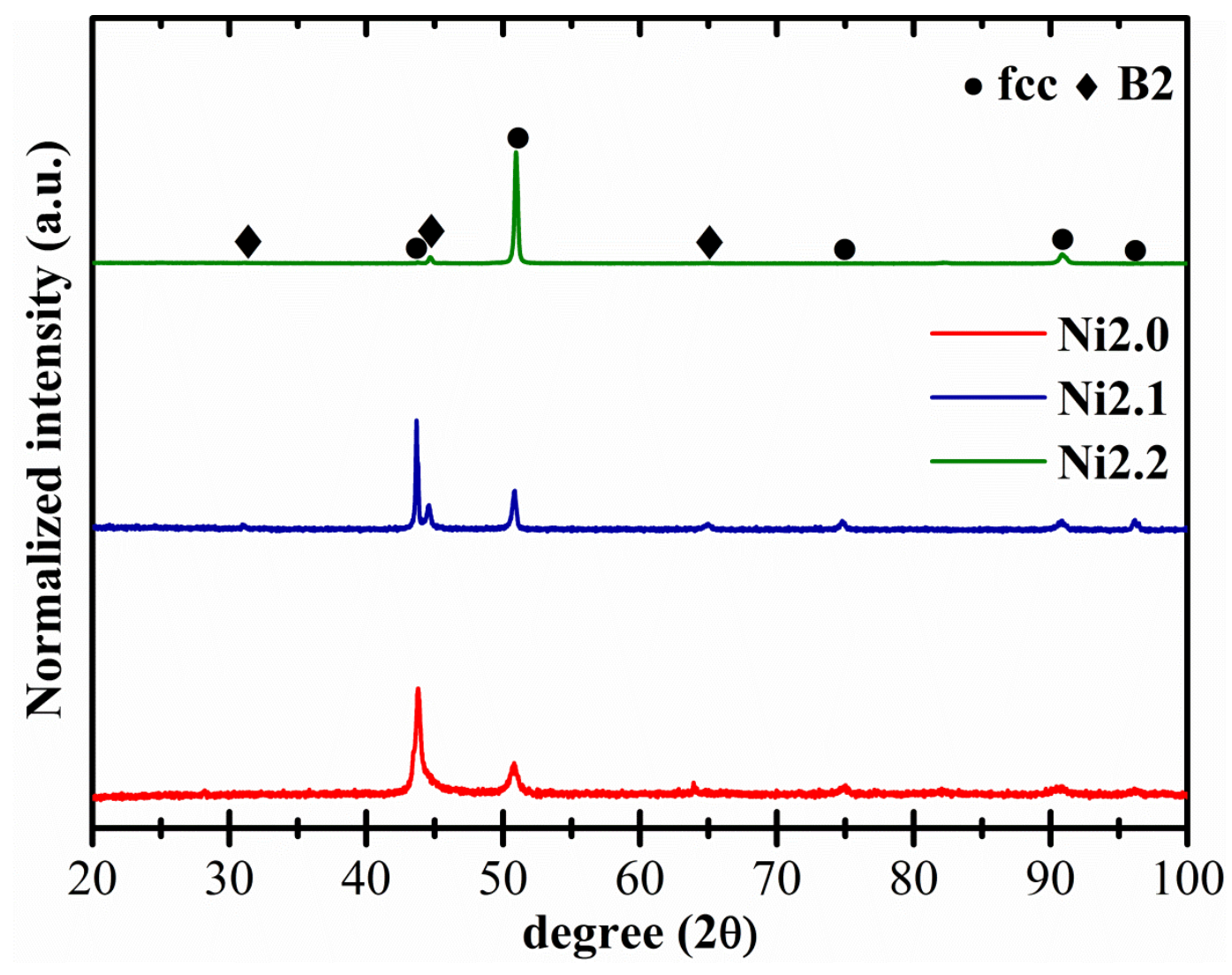


Lu YP, et al., Fig. 3(a,b,c)
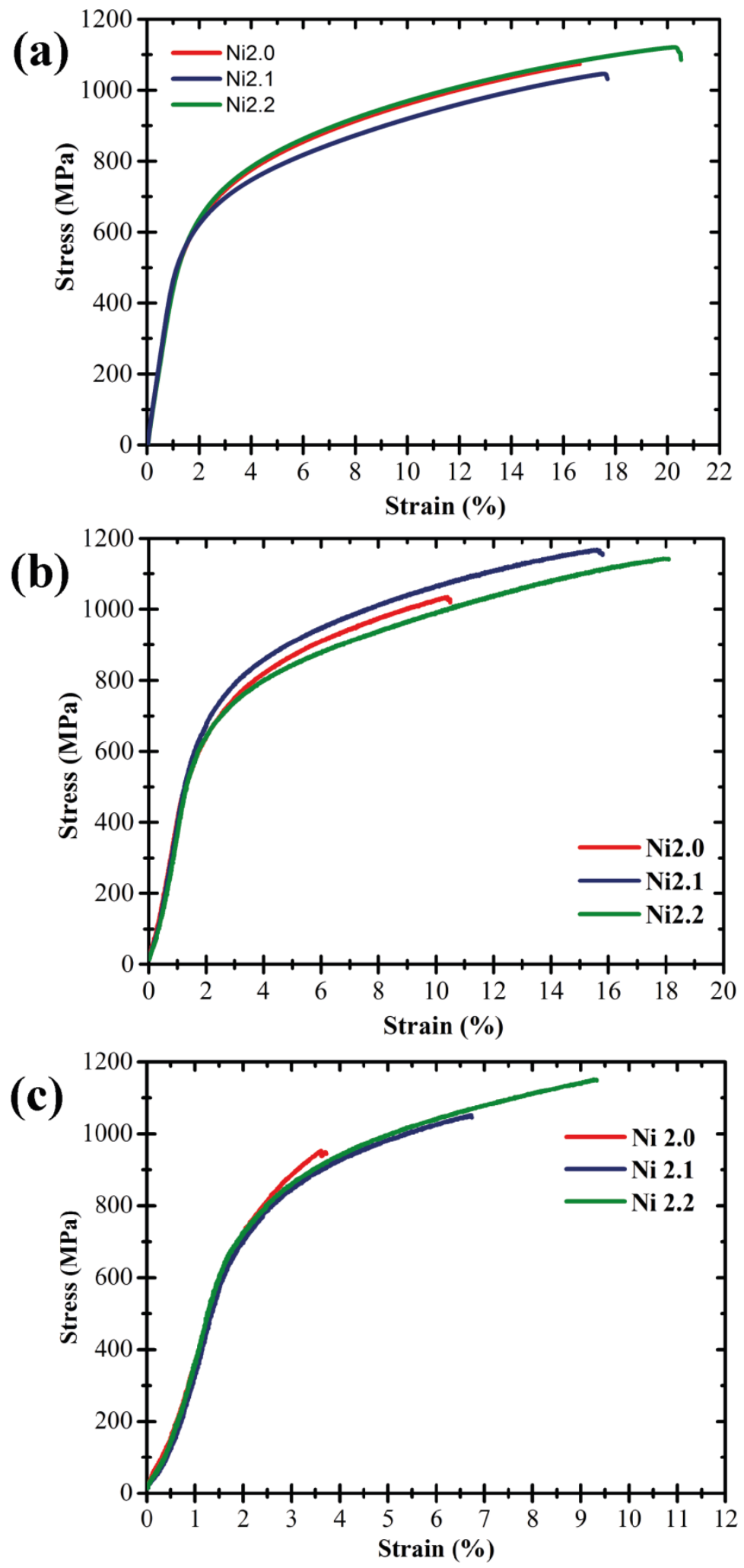
Lu YP, et al., Fig. 4(a,b,c)

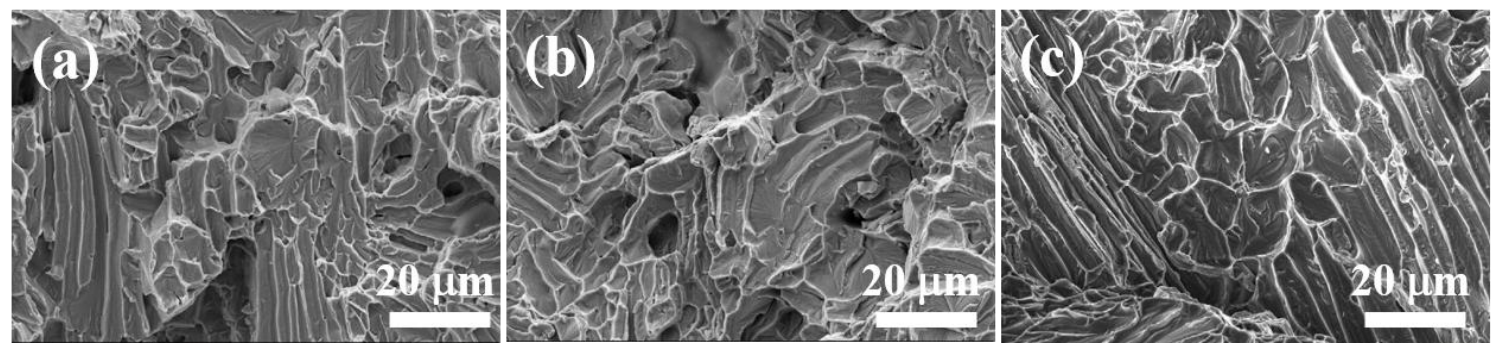


Lu YP, et al., Fig. 5(a,b,c,d)
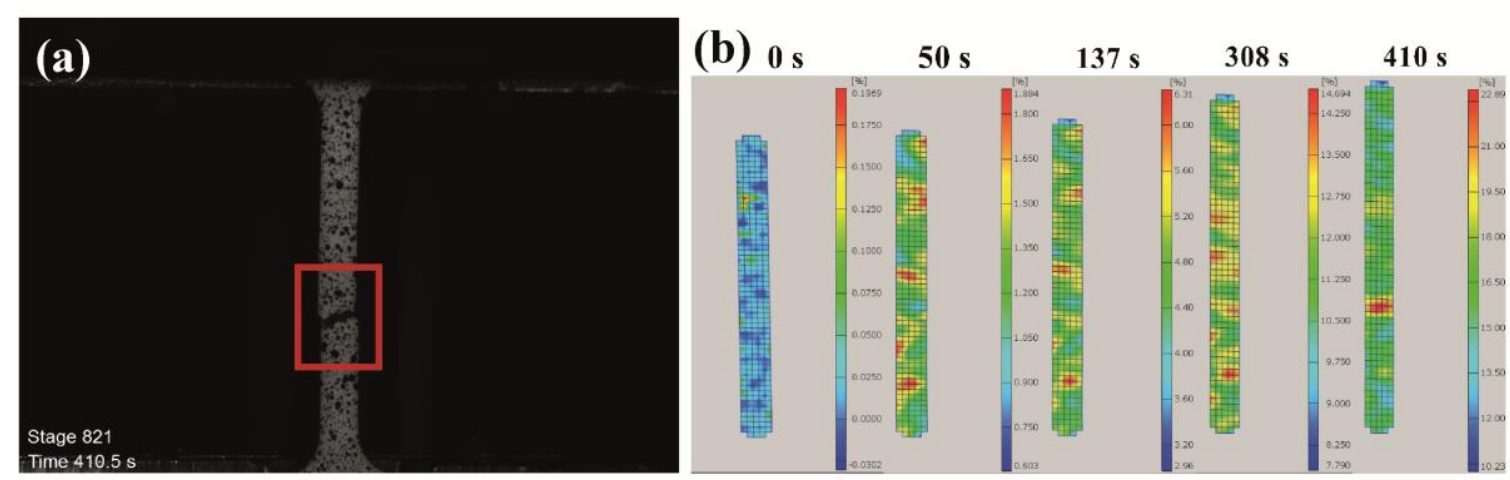

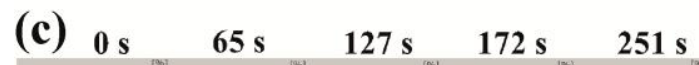

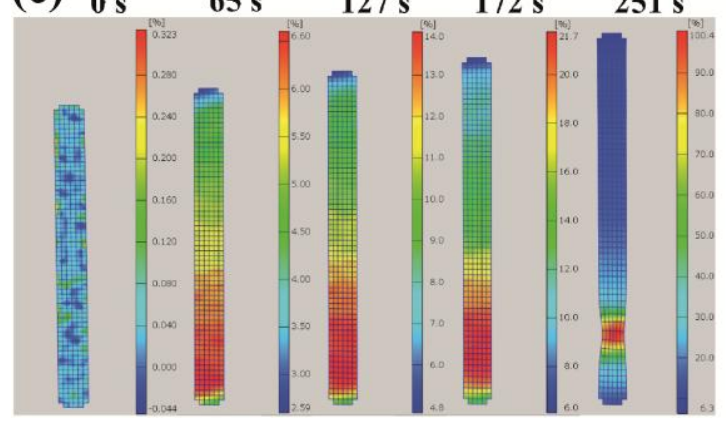

(d) $0 \mathrm{~s}$

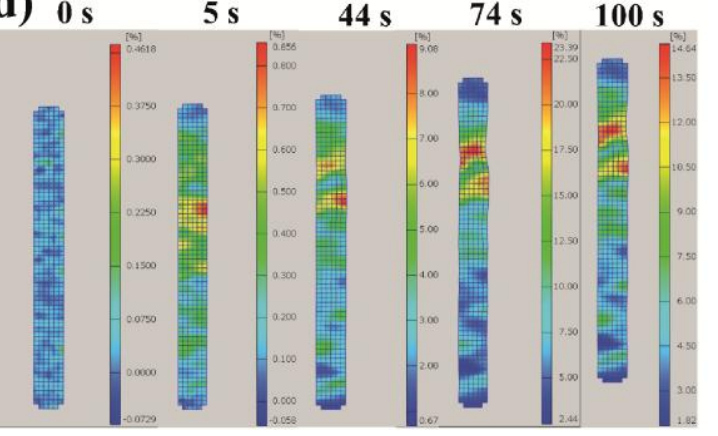




\section{Lu YP, et al., Fig. 6 (a,b)}
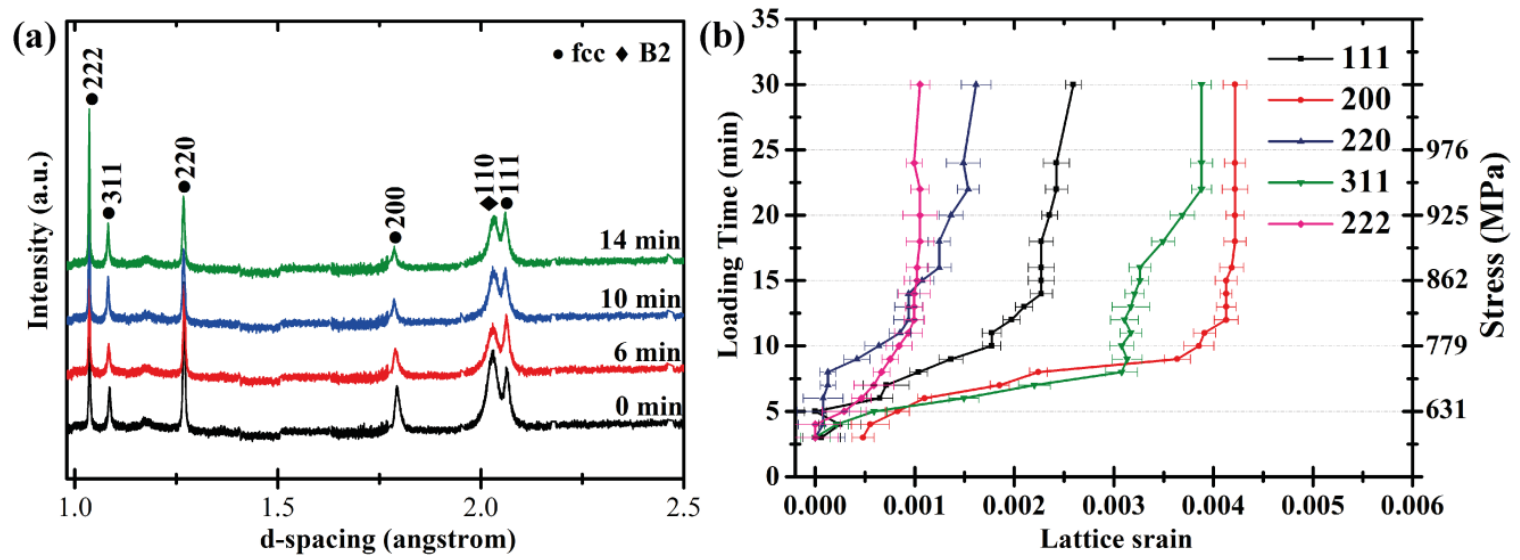
Lu YP, et al., Fig. 7(a,b)
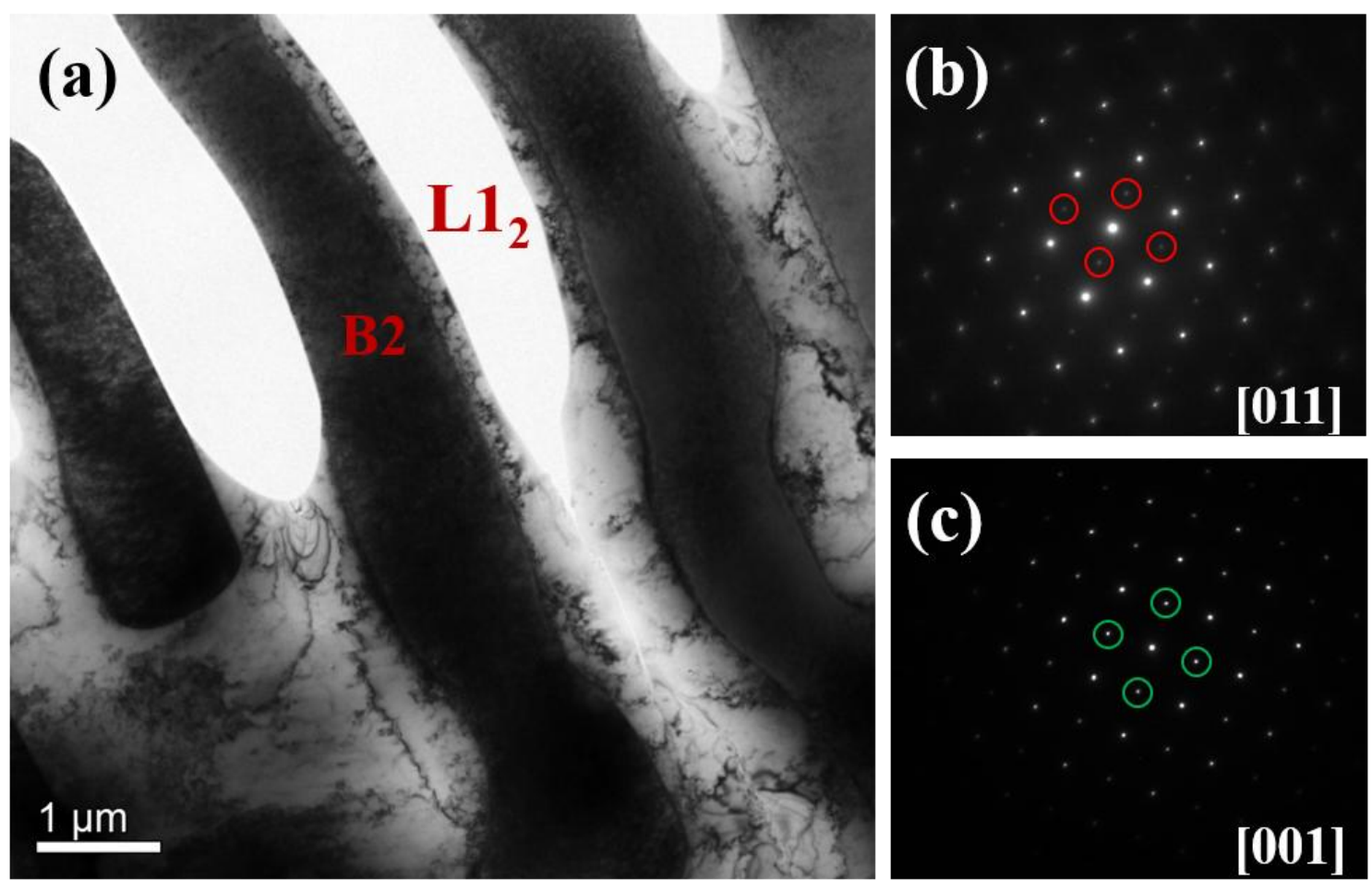
Lu YP, et al., Fig. $8(a, b)$
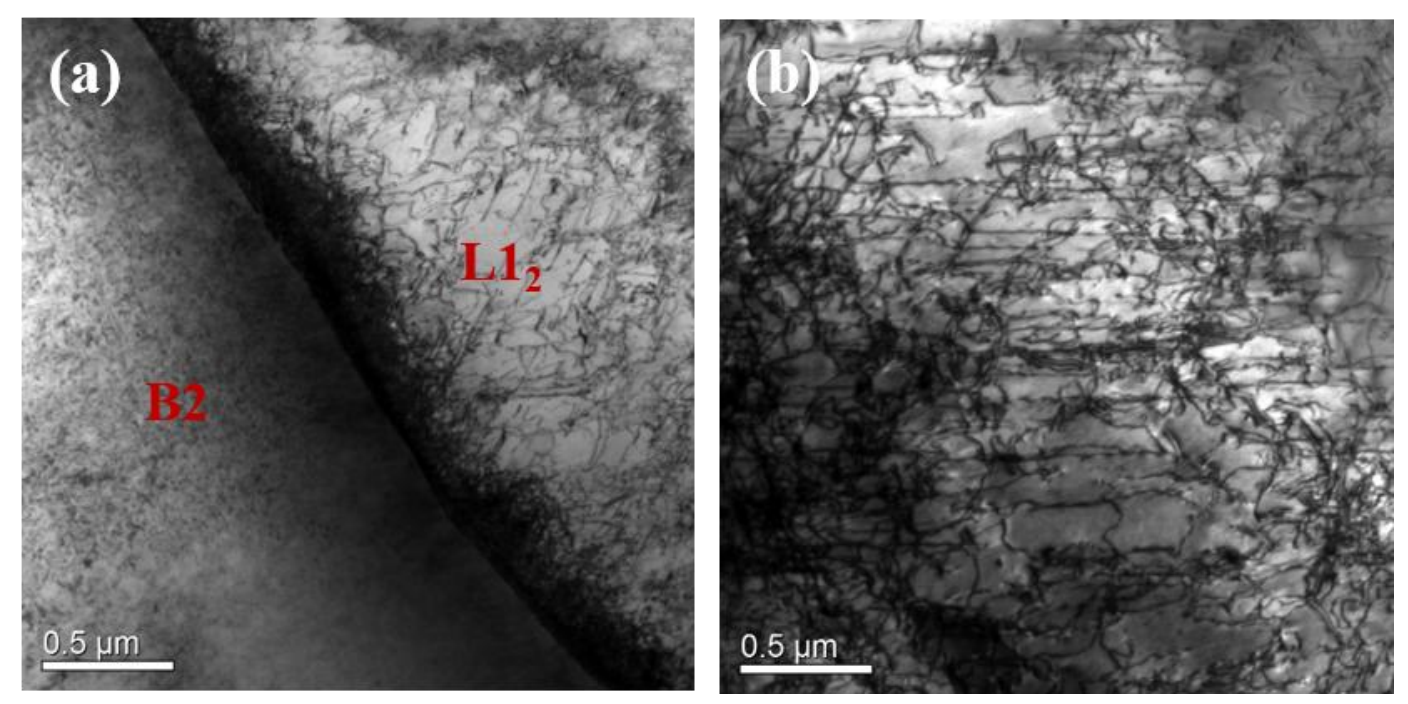
Table 1 Yield strength, fracture strength and elongation (EL\%) to fracture of Ni2.0, Ni2.1 and Ni2.2 alloys at room temperature (RT), and -70 and $-196{ }^{\circ} \mathrm{C}$

Test temperature Alloys $\sigma_{\mathrm{y}}(\mathrm{MPa}) \sigma_{\mathrm{UTS}}(\mathrm{MPa})$ EL\%

\begin{tabular}{|c|c|c|c|c|}
\hline & Ni2.0 & 545.6 & 1076 & 16.6 \\
\hline \multirow[t]{3}{*}{ RT } & $N i 2.1$ & 546.4 & 1046 & 17.7 \\
\hline & $\mathrm{Ni2} .2$ & 544.5 & 1120 & 20.5 \\
\hline & $\mathrm{Ni2.0}$ & 580 & 1034 & 10.5 \\
\hline \multirow[t]{3}{*}{$-70^{\circ} \mathrm{C}$} & $\mathrm{Ni2.1}$ & 595 & 1168 & 15.8 \\
\hline & $\mathrm{Ni2.2}$ & 570 & 1143 & 18.0 \\
\hline & Ni2.0 & 715 & 952 & 3.7 \\
\hline \multirow[t]{2}{*}{$-196{ }^{\circ} \mathrm{C}$} & $N i 2.1$ & 690 & 1051 & 6.7 \\
\hline & $\mathrm{Ni2} .2$ & 705 & 1151 & 9.3 \\
\hline
\end{tabular}


Lamellar structure in the AlCoCrFeNi ${ }_{2.1}$ EHEA, Nakazima test results measured at different time steps (stages) during tension, presenting a unique wave-like distribution, and tensile testing results at room temperature, $-70^{\circ} \mathrm{C}$ and $-196^{\circ} \mathrm{C}$.
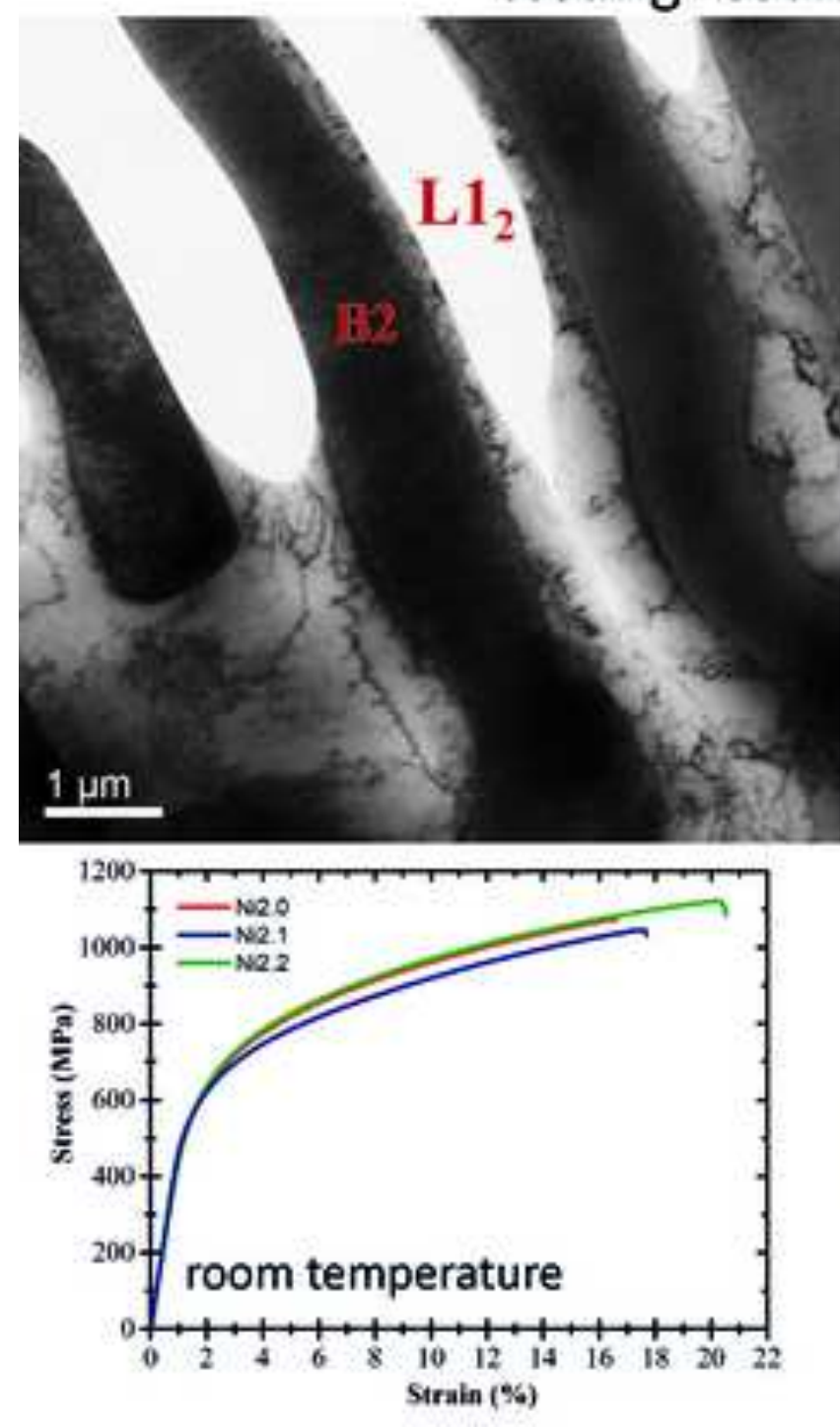
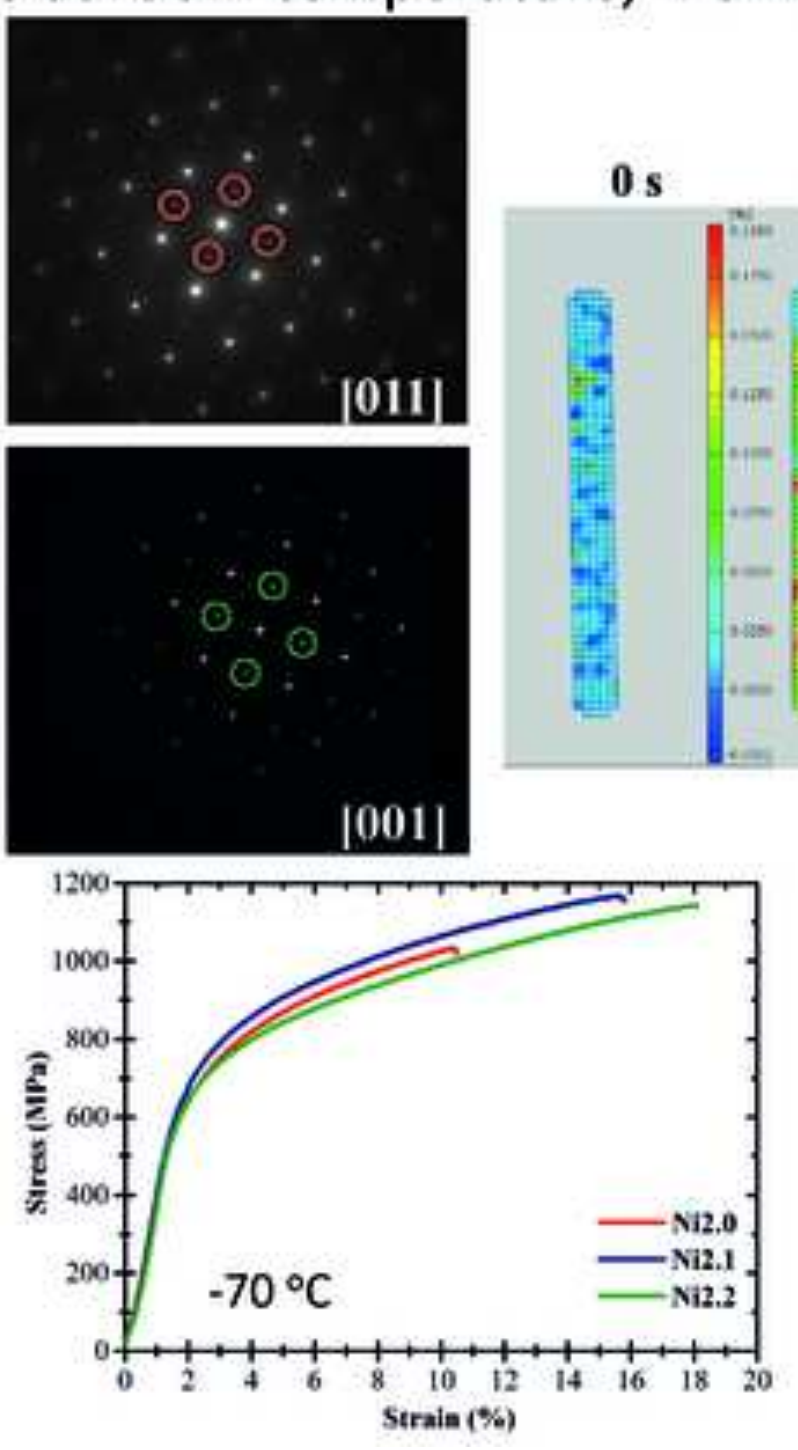
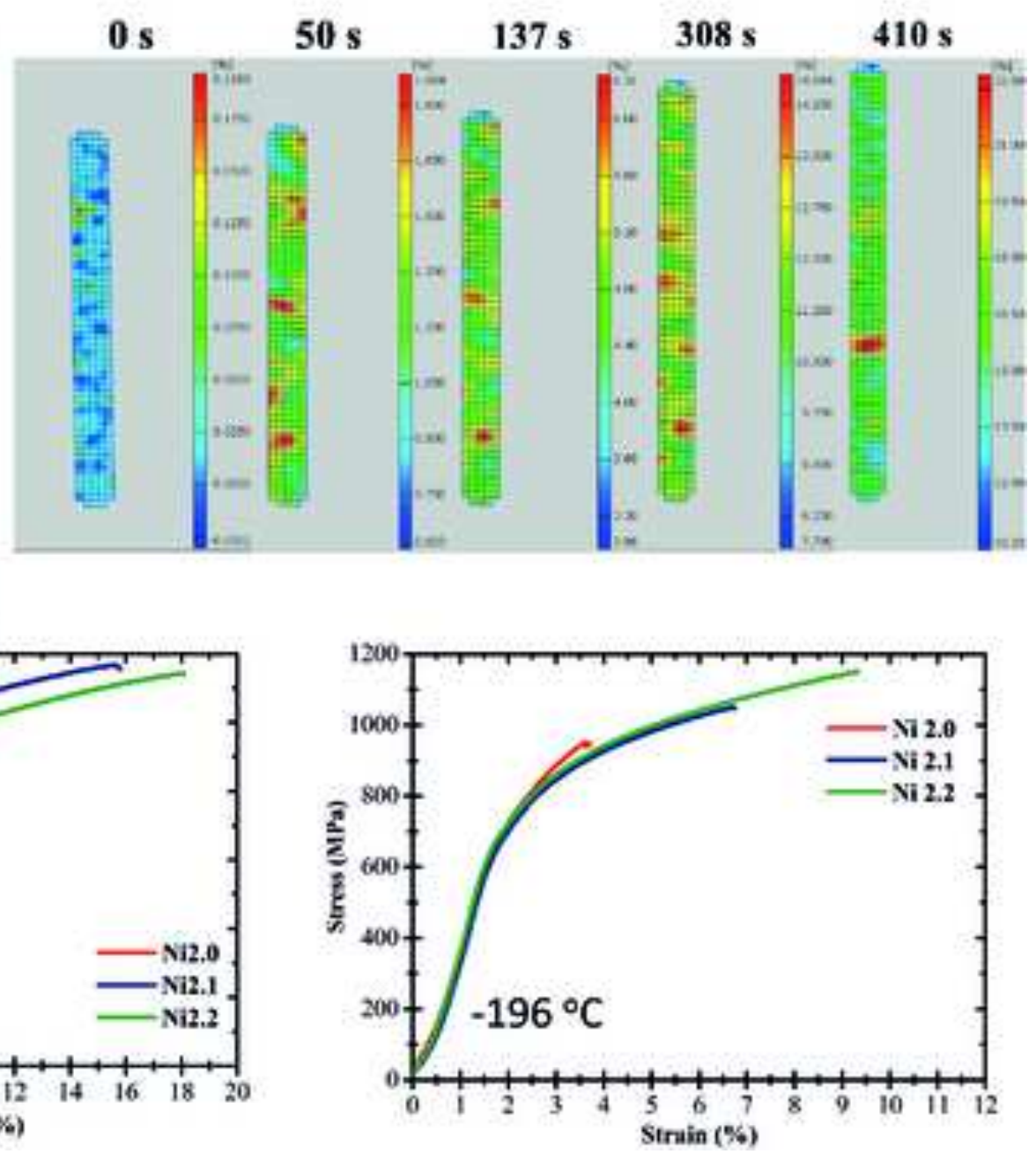